\title{
The institutional challenges of participatory communication in international aid
}

\author{
Silvio Waisbord* \\ School of Media and Public Affairs, George Washington University, Washington DC, USA
}

(Received 15 February 2008; final form 25 March 2008)

This article offers an explanation for the limited uses of participatory communication in development by taking an institutionalist perspective that examines prevalent notions about communication and organizational uses in international aid institutions. The argument is that institutional goals and dynamics determine the use of disciplinary and theoretical approaches. The selection of specific communication approaches is not primarily based on their analytical or normative value, but rather, on institutional factors and expectations. Institutional dynamics undercut the potential contributions of participatory communication in three ways. First, bureaucratic requirements favor the use of informational models over participatory approaches to communication. Standard institutional procedures inside development agencies, donors and governments perpetuate understandings and uses of communication as a set of technical skills to disseminate messages. Second, the weak status of communication as a field of study and practice in development organizations undermine the prospects for expanding the understanding of communication that do not fit prevalent institutional expectations. As long as technical experts in public health or other fields expect communication to be 'the art of messaging,' communication staff lacks autonomy to make decisions and incorporate participatory approaches. Third, the institutional predominance of a technical mindset also limits the uses of participation thinking. The prioritization of technical perspectives decouples 'development' programs from local processes of participation and change.

Keywords: participatory communication; professionalism; international aid

In the mid-1970s, Everett Rogers (1976) affirmed that the dominant paradigm in development communication had passed. Rogers specifically referred to the rise of participatory approaches that challenged 'diffusionism' studies that had been dominant since the 1950s. Coming from Rogers, a seminal figure in the 'diffusion' tradition, that affirmation was significant. It did not only acknowledge the limitations of the approach that Rogers had pioneered, but it also recognized the merits of theories that foreground community participation and socio-economic structures in the analysis of communication processes. More than three decades later, it is worth revisiting Rogers' assessment in light of considerable scholarly attention and programmatic experiences in development. Since its beginnings, development communication has been both a field of knowledge and practice. It included academic research as well as programs in international organizations and governments. On the one hand, bridging theory and practice has been a constant preoccupation among researchers (Wilkins, 2000). Academic scholarship was not

\footnotetext{
*Email: waisbord@gwu.edu
} 
conceived as a mere intellectual exercise, but rather, it maintained a constant dialogue with programmatic practice. It talked about specific experiences and, frequently, hoped to make an impact in development programs. On the other hand, practitioners in international aid programs and civic organizations have regularly reached out to scholars to collaborate on research, evaluation, and training.

My interest in revisiting Rogers' observation has been stimulated by my recent experience working for a non-profit organization in communication and development programs. After teaching and conducting research in academia for two decades, I worked on advocacy, communication and social mobilization in health in Africa, Asia, and Latin America between 2002 and 2007. I collaborated with UN agencies, bilateral and multilateral donors, governments, and civic organizations (e.g. faith-based, professional, educational institutions). During that time, my firsthand observations made me increasingly skeptical about Rogers' conclusion about 'the passing of the dominant paradigm' given that diffusionist premises typically underpinned global health programs. I encountered programs to promote institutional childbirth in the Peruvian highlands, inform couples about family planning in Bolivia, or convince Angolan mothers to get children immunized were similarly intended to disseminate information with the hope of changing knowledge and practices. Only exceptionally interventions were expected to do more than disseminate information to communities and other actors (e.g. journalists, political and religious leaders) about the benefits of certain health practices, drugs, and technologies. Eventually, I became convinced that Rogers' assertion applies to academic discussions better than to communication programs in international aid.

No question, 'diffusionist' perspectives are hardly dominant in academia as they were back in the heyday of modernization theory when Daniel Lerner and Wilbur Schramm confidently argued that 'modern communication,' basically the mass media, was the harbinger of modern development. In the past decades, participatory communication and other critical approaches informed by gender and post-colonial studies have enriched the field by raising new questions and opening analytical dimensions ignored by 'diffusion' studies (Morris, 2003; Wilkins \& Mody, 2001). By offering a biting critique of diffusionism and modernization as the intellectual mothership, critical studies have questioned the purpose of the entire 'development' enterprise (Escobar, 1995). This critique underlies recent calls to drop the notion of 'development' in favor of 'social change' and 'social justice'. 'Development' is seen as inescapably tainted by the patronizing ideology of modernization and beyond rehabilitation. Despite the strength of 'post-development' arguments, it would be exaggerated to conclude that 'the dominant paradigm' has passed. In fact, as Rogers (2004) proudly underscored shortly before his death, there has been a tremendous growth in 'diffusion' studies across the social sciences and the health sciences in the past decades. Although academic debate and research on communication and 'development' is no longer dominated by a single theoretical approach, the situation is different in the practice of 'communication' in the international aid system. Participatory communication and similar approaches premised on the notion that 'communities need to be the protagonists of development and social change' are rare (Gumucio-Dragon, 2001).

In this article, my interest is to explain the limited uses of participatory communication in development by taking an institutionalist perspective that examines prevalent notions about communication and organizational uses in development institutions. Why do informational approaches still exert considerable pull? What conditions discourage the adoption of participatory communication? These are the questions that guide the analysis. The conceptual premise is that to assess the impact of academic research it is necessary to situate communication as a field of practice in the institutional settings of programs and 
agencies. Little could be understood about the use of theoretical models without assessing the institutional place of communication in international development. The incorporation of 'participatory communication' in 'development' programs offers an opportunity to study the impact of intellectual trends on international organizations. Explaining this choice requires understanding institutional dynamics and mandates inside 'development' organizations. This topic, unfortunately, has not drawn much interest from the communication literature, a remarkable gap considering the perennial interest among scholars to bridge theory and practice. Although much has been written about trends in academic research and the impact of specific programs, little research has been conducted on development communication from an institutionalist perspective that examines 'how agencies work.' From this perspective, the premise is that institutional goals and dynamics determine the use of disciplinary and theoretical approaches. The selection of specific communication approaches is not primarily based on their analytical or normative value, but rather, on institutional factors and expectations.

Given my experience and the long and rich history of communication in health, the analysis focuses on the uses of communication approaches in global health programs. This article begins with placing the uses of participatory communication within the broader incorporation of participation in development programs. The analysis then explores why informational approaches are typically preferred over participatory models. It concludes by outlining ways to envision the expansion of communication thinking and practice in development.

\section{The diffusion of participatory communication}

The main analytical thrust of participatory communication and its ascendancy in development studies have been summarized elsewhere (Jacobson \& Servaes, 1999; Waisbord, 2000; White, 1994). For the purposes of this article, suffice to mention basic principles about the theoretical underpinnings and intellectual trajectory of participatory communication.

Participatory communication posits that communities should be the main protagonists of processes of social change rather than 'passive beneficiaries' of decisions made by foreign experts. In this sense, it questions the view of development as an externally-driven process planned and implemented by Western technical experts. For participatory theorists, 'developmentalism' offers a patronizing approach that assumed that outside expertise 'know better' than communities. Second, participatory communication proposes a 'communitarian' view that makes deliberation and participation in public affairs, rather than information-transmission (including message design and media technologies), the essential elements of communication. Third, participatory communication conceives 'development' as a transformative process at both individual and social levels through which communities become empowered. This differs from the view that links development to the achievement of economic progress and political institutions associated with Western democracies. Fourth, participatory communication promotes local forms of knowledge and action as the springboard for social change. This view is in sharp contrast with modernization and diffusionism that basically see local cultures as obstacles to progress and development.

Standard accounts frequently refer to experiences in Latin America in education and agrarian development in the 1960s and early 1970s as pioneering examples of participatory communication (Gumucio-Dragon, 2006; Mato, 2004). Paulo Freire's ideas about 'critical consciousness' in education and Orlando Fals Borda's critical approach to participatory 
development have been credited for introducing novel ideas in development communication. In contrast to mainstream communication studies in US universities, Latin American communication research and practice moved two analytical issues to the forefront: the unequal structures of media systems, and the role of social agency as demonstrated by popular media and social movements (particularly the experiences of indigenous movements and trade unions). Intellectually, participatory communication dovetailed with similar approaches from other disciplines that championed the need to put communities at the center of processes of social change and criticized top-down development promoted by international agencies. Arguments about the need to strengthen community-based health programs and farmer-centered agricultural initiatives, for example, also emerged as critical responses to conventional models that prized experts and dismissed local knowledge. Just as local participation could determine best-suited strategies for increasing agricultural productivity, it could also strengthen healthcare initiatives in ways that communities take power away from states and experts.

Three decades later, one can hardly doubt that participation has made substantial inroads in development programs. Robert Chambers (2007), one of the leading figures in the participatory tradition, has recently written that development agencies and professionals 'are becoming more participatory.' Standard accounts agree that participatory ideas have gradually moved into the mainstream of development studies and the system of international development (Blanchet, 2001; Robb, 2002). The increasing number of participatory experiences has stimulated a rich and unfinished debate about the consequences of the incorporation of participation in international aid programs. Critics have argued that the aid system has adapted an instrumental notion of participation as a means to achieve predetermined ends. The institutionalization of participation brought about the flattening of its radical premises in order to make it a more malleable and ultimately ineffective approach that would not question the central premises of 'developmentalism' (Escobar, 1995). Development programs have depoliticized participation by stripping its radical dimensions related to power distribution and collective action (Cleaver, 2001; Hickey \& Mohan, 2005). Consequently, participation has become a meaningless and bland term, a decorative piece in a system that continues to keep states, agencies, and experts in control. What was once a subversive position that aimed to turn development upside down, participation has become part of the discursive disguise of 'developmentalism,' a mere rhetorical piece in the service of neo-liberalism and policies imposed upon communities around the world (Cornwall, 2007; Leal, 2007; Sachs, 1991). Critical communication scholars have made arguments along similar lines. They suggest that the aid system has co-opted participation and eviscerated its political implications, and has manipulated participatory ideas in 'development communication' (Huesca, 2003; White, 1999). For them, participation is incompatible with informational techniques routinely used in development programs and the overall goals of the development regime, such as the promotion of global trade and the opening of economic and financial markets (Melkote \& Steeves, 2001). Although those statements identify important limitations of the uses of participation, they are sweeping generalizations that do not render a nuanced picture of the institutional uses of participatory communication. Because such conclusions are formulated at a general, abstract level, they fail to acknowledge variations and tensions. Also, they attribute duplicity in the uses of participation where it might not necessarily be there. If international agencies engage in double-talk about participation, it might not necessarily be the result of underhanded, malevolent intentions, but rather a response to organizational procedures and imperatives. 
To assess the uses of participatory communication, it is necessary to examine communication programs within the organizational context of international agencies. An institutionalist perspective helps us to understand why 'informational' communication prevails over participatory communication in development agencies. Institutionalist approaches have showed the importance of bureaucratic dynamics to understand changes in both the agenda and the functioning of development organizations (Ellerman, 2006; Edwards, 1999). The combination of pressures to 'move money,' the lack of coordination within and across institutions, and unwillingness to devolve control to communities prevails over considerations about programmatic goals and strategies. Attention to bureaucratic dynamics also allows us to understand obstacles and opportunities to foregrounding participatory communication. Institutional imperatives are responsible for why essential participatory ideas, namely local knowledge and decision-making, are rarely at the forefront of development initiatives. A system of bureaucratic procedures that rewards institutional efficiency weakens community empowerment, and reduces participation to publicity copy. The remainder of this article examines the bureaucratic imperatives that constrain the incorporation of participatory communication and continue to favor informational approaches.

\section{The uses of participatory approaches in communication programs}

Although participation is essentially about, as Robert Chambers (1997) put it, 'whose reality counts?', the literature identifies three key dimensions of participation in development programs (Uphoff, 1985). First, it refers to the centrality of local knowledge in determining problems, identifying solutions, and assessing results. Communities, rather than experts or other external agents, should determine challenges and decide appropriate courses of action to tackle problems through dialogue and critical thinking. Second, communities have a protagonist role in making decisions about the goals and the direction of programs and actions. If decisions are left to agencies and their cadres of professionals, programs and actions are disconnected from the actual motivations and expectations of communities. Third, communities need to be involved in the implementation of activities. When actions are conducted by external actors, communities are displaced to a secondary role and thus remain distant from actions that are, in principle, designed to have an impact on their lives. Empowerment is the result of the process by which communities decide what to do, lead where to go, and are involved in actions.

Participation plays a weaker role in the first two components than the third one. Available evidence suggests that development programs are more likely to feature active communities involved in the implementation of activities rather than assessing problems and solutions or making decisions about goals (Holland \& Blackburn, 1998). Participatory action research and similar methodologies that foreground community knowledge are circumstantially used, but they are rarely the starting point. Only a few of the experiences that I participated in started from local assessments such as a multi-year project that brought together universities, local governments, and civil society in Peru as part of a local process of mobilization to define health needs and goals as part of the national process of decentralization of health services (Waisbord, 2006), or community-based experiences to control dengue in various countries in Central America. Instead, programs typically followed pre-established goals decided at the national, regional, and/or global levels such as improving tuberculosis control or reducing child mortality. Programs are hardly subjected to the 'tyranny of participation,' as Bill Cooke and Uma Khotari (2001) have argued. In fact, participation understood as the prioritization of local knowledge and local 
needs is rarely a driving factor. Nor are programs constrained to pay lip-service to participation. More typically, instead, international agencies (technical organizations, donors) and national governments carried out programs that had been previously agreed upon in global agreements and national policies. Thus, communities are not in the lead in making decisions about programmatic goals. Agencies and donors wield power in the definition of goals, budgets, management, and the overall direction of programs. Likewise, decisions to step up current efforts to reduce the burden of HIV/AIDS, tuberculosis, maternal mortality, and child mortality have not been the result of extensive community consultation and agreements across the globe. Rather, they were the product of complex negotiation and advocacy involving governments, bilateral and multilateral donors, UN agencies, and in some cases, the mobilization of affected communities.

Although community participation is rarely central to the identification of problems and goals, it has become increasingly important in the implementation of health programs. Social mobilization is central to health campaigns such as ongoing efforts to eradicate polio and measles in which local resident staff vaccination teams bring out neighbors to vaccination booths, distribute information, and so on (Waisbord, 2008, forthcoming). Likewise, local participation is prominently featured in numerous educational efforts to bring awareness about HIV/AIDS prevention and treatment as well as women's health issues at the community level. Communities conduct peer education, street theater and cinema, and popular radio shows, all of which are staple communication activities of many health programs around the world (Tufte \& Hemer, 2005). Also, communities are actively involved in the implementation of advocacy actions to raise awareness about specific health issues, stimulate deliberation, and promote changes in laws and policies that affect access to and the quality of healthcare. Current activism around HIV/AIDS, tuberculosis, and a host of women's health issues (e.g. female genital cutting, domestic rape, family planning) in international programs suggest that affected communities are not always 'passive beneficiaries' of development interventions (Davenport, McKinley, Ventsam, \& Elias Valdeavellano, 2002).

To dismiss these participatory experiences as 'mobilization without empowerment' is misguided. Whether they only function as transmissions lines of top-down projects (Macdonald, 1995; Moxham, 2005) or effectively build a sense of empowerment and civic participation beyond the time span of a single program cannot be inferred from their original intentions. Consider the case of polio vaccination campaigns in Nigeria and India in recent years. Even when goals such as the global eradication of polio had been endorsed by national governments, international agencies and donors have faced difficulties in achieving goals that do not match community priorities. The decision to conduct numerous annual immunization rounds to vaccinate children against poliomyelitis, a terrible disease but hardly a major cause of morbidity and mortality around the world, has been met with disinterest, distrust and resistance in many communities (Waisbord, 2008, forthcoming). Polio eradication is hardly an urgent preoccupation in communities ravaged by poverty and diseases such as malaria, respiratory ailments, and chronic gastrointestinal problems rooted in poor nutrition and lack of access to safe water and appalling sanitation. Only after local leaders mobilized against polio immunization due to concerns about vaccine safety and rumors about a 'Western campaign' to sterilize Muslims, immunization campaigns decided to promote other services (e.g. insecticide-treated bed nets, the building of latrines) that did meet local demands. Campaign planners realized that in communities with appallingly weak health services, it was not just a matter of showing up with medicines and expecting that people would diligently accept them. Consequently, governments and donors decided to incorporate other services during immunization 
days, change the ethnic and gender composition of vaccination teams, and promote intense social mobilization. These decisions were the result of intense negotiation between communities with government and international agencies after the former refused to accept polio vaccinations. The experience of global polio eradication suggests that the priorities of agencies and donors may run against a different set of local needs. Just because national governments endorse specific global goals and strategies, it does not follow that communities, who are represented by those governments in international forums, would necessarily agree with those decisions. Local resistance might not force international agencies to change priorities or technical mindsets, but rather, they have been able to demand additional services.

Evidence from global health programs suggests that participation has been incorporated mainly as the involvement of communities in programs whose goals are largely defined by the international aid system. Although communities may decide what problems to tackle and set goals, they are rarely on equal footing to outline the mission of development and foreign aid with international agencies, donors, governments, and technical staff.

The next section explores three institutional imperatives that discourage the expansion of communication beyond the informational paradigm and limit the adoption of participatory communication. My argument can be summarized as follows. Institutional dynamics undercut the potential contributions of participatory communication in three ways. First, bureaucratic requirements favor the use of informational models over participatory approaches. Standard institutional procedures inside development agencies, donors and governments perpetuate understandings and uses of communication as a set of technical skills to disseminate messages. Second, the weak status of communication as an autonomous field of study and practice in development organizations undermines the prospects for expanding the understanding of communication that does not fit prevalent institutional expectations. As long as technical experts in public health or other fields expect communication to be 'the art of messaging,' communication staff lack autonomy to make decisions and incorporate participatory approaches. Third, the institutional predominance of a technical mindset also limits the uses of participation thinking. The prioritization of technical perspectives decouples 'development' programs from local processes of participation and change. The following sections examine these three obstacles.

\section{Bureaucratic needs for messaging}

Bureaucratic interests tilt the balance in favor of informational over participatory approaches to communication. David Mosse's (2005) reflections on the obstacles for integrating participation in a rural development project in India offer a useful point of comparison to understand the institutional limitations for participatory communication. Mosse demonstrates that although the project originally embraced participatory ideas, it failed to meet its rhetorical promises. Institutional difficulties were responsible for the contradictions between the original design and the reality of the program. Even when key parties were committed to making participation central, turning it into a concrete action was fraught with problems. Participation was viewed as a too time-consuming approach that required intensive use of human resources. Officials were doubtful about a participatory approach given the limited scale of the program and the difficulty for replicating it in other communities. Given institutional requirements for large-scale success, they were reluctant to fully endorse a 'niche' project that despite its achievements could not 
receive positive reviews due to its 'small' scale. Mosse also calls attention to the fact that participatory communication posed another challenge to technical programs: unpredictability. By definition, participatory communication contains the possibility of unexpected occurrences. Dialogue and negotiations may result in demands that do not match the intentions and mandates of international agencies. Participation contemplates the possibility that communities may question problem assessments produced by international agencies or government, and/or dispute control over programmatic goals. The inherent messiness and uncertainty of participative processes clashes with the bureaucratic logic of rationality and predictability that governs development agencies. Participation may interfere with the normal functioning of procedures including contracts, program design, scheduling, implementation, and funding.

Thus, participatory communication runs contrary to a mentality that prioritizes achieving rapid results within time-bounded funding cycles. The timeline of budget allocations does not match the pace of social change. Pressures for smooth approval and roll-outs of projects and funds require avoiding potential delays that might result from extensive consultation, especially if community demands contradict institutional mandates. Whereas programs that jump successfully over institutional hurdles are rewarded, delayed and unmanageable programs bring headaches. Further, social change and institutional careers follow different tracks. Short-term attention to institutional and individual priorities runs counter to the long duration of social change. Annual earmarks undermine long-term planning and processes. Professional incentives often determine changes in program orientation, approaches, 'targeted' communities, and the selection of partnering agencies. Officers aiming to put their personal stamp on programs during their tenure may decide to shift previous commitments on the basis that they were projects that 'belonged' to their predecessors, or that specific ideas and organizations had already received sufficient support over the years.

In contrast, informational approaches to communication find a more hospitable environment. They are expected to support tangible and priority institutional demands. While participatory communication may bring up unpredictability, 'informational' communication aims to ensure a controlled environment. It responds to the organizational need for visibility and reputation in an age of public relations (Cottle \& Nolan, 2007). Raising the public profile and building 'organizational brands' are important for development agencies and individual programs. Communication officers are expected to 'get the name out' through publicity materials and news events, and manage potential conflicts caused by opposition to programmatic goals (e.g. selective administration of antiretroviral drugs, costs of health services), ethical lapses (e.g. corruption, mismanagement, nepotism), and procedural failures (e.g. distribution of unsafe vaccines, drug stockouts). Gaining recognition and prestige are important to generate favorable opinions among key actors (e.g. government officials, funders, other agencies and programs) whose decisions affect institutional mandates and budgets.

Also, 'informational' communication fits institutional needs in the current environment of an international aid system dominated by vertical and separated initiatives. Compartmentalized, disease-specific programs that pursue separate goals and deliver medicines and service outside health systems are typical in global health initiatives. Measles and polio programs aim to augment rates of measles immunization (rather than general vaccination rates). HIV/AIDS and TB programs aim to increase the number of cases detected and under treatment (rather than strengthening infectious diseases programs). Critics have observed that a mindset that rewards disease-specific indicators drives out interest in tackling problems across health programs such as collapsed primary health services or the 
'brain drain' in global healthcare systems (Garrett, 2007). Thus, resource-rich programs that get the lion's share of public attention and funding stand out amidst skeletal programs and dilapidated health systems. My point is not to reiterate these criticisms, but rather to underscore that the current silo-like structure offers institutional incentives in favor of 'informational' communication. The fragmentation of public health in vertical programs stimulates territorial politics, battles over budgets and influence, and a constant race for public visibility. Competition over financial and publicity across programs is all too common. A focus on specific diseases drives the need for fund-raising and elevating the public profile of programs. In this context, communication is expected to help vertical programs stand out, compete for funds, and advocate among policy-makers and donors.

Given organizational expectations for publicity, it comes as no surprise that 'communication' is typically housed in 'external/public relations' units in the organizational chart of development agencies and governments. Although some international organizations have had 'program communication' units, typically, communication is equated with 'press offices' that perform public relations. ${ }^{2}$ Organizational positioning is not insignificant considering that it affects the content of workplans, annual reviews, staffing, job descriptions, budgets, and so on. Furthermore, it affects the ability to promote changes in international agencies (Bebbington, Guggenheim, Olson \& Woolcock, 2004).

\section{Communication, a subsidiary discipline}

When communication is expected to support 'technical' rather than 'organizational' goals, institutional demands and professional cultures still define its goals. The literature has rarely acknowledged the obvious fact that communication programs function in organizations that do not aim to achieve communication goals. Instead, they set out to achieve objectives in diverse areas such as health, education, governance, environment, agricultural productivity, and economic reform. Communication goals are hardly a main priority for the international aid system. Although development goals have changed over the years, communication objectives have not been central to the mandates of UN agencies (with the exception of UNESCO and UNPD) or the largest bilateral and multilateral donors. Communication remains absent in major global development documents such as the Millenium Development Goals, the blueprint that defines 'development' objectives for 2015.

As long as development goals are defined in terms of specific indicators in technical areas, communication is expected to support, rather than to lead, programs. Thus, housed in health, financial or agricultural organizations and programs, and cast in the role of a subsidiary discipline, communication lacks autonomy to determine goals and approaches. Instead, technical staff whose expertise lies in other disciplines and are responsible for managing programs, have authority over communication. If development goals are measured by health indicators (e.g. the percentage of AIDS patients who complete treatment) or educational indicators (e.g. the percentage of girls who complete primary education), then, communication is expected to contribute to those goals. Program officers trained in various fields are often responsible for determining goals and approving decisions about the goals of communication. Economists may ask communication to help ensure that local governments and civic organizations collaborate in moving loans through the approval process. Health officers may expect communication activities to increase demand for new drugs and commodities (e.g. condoms, bed nets), change child feeding habits, and educate populations about medical regimens. Agricultural specialists may request communication to promote the use of new seeds and fertilizers. Thus, 
communication is expected to meet programmatic goals and utilize approaches that fit existing conceptions among technical staff. Whether communication interventions actually promote participation is less important than their contributions to technical goals. Promoting egalitarian relationships in households, helping community organization and mobilization, facilitating dialogue are secondary to meeting technical objectives.

The weak professional status of communication in development agencies further undermines the possibility that communication could set out goals that are not aligned with the dominant technical mindset. Professions claim social and cultural authority over certain practices and forms of knowledge. As sociologists have argued, professions exercise 'organized autonomy' as they claim exclusive jurisdiction in a field of knowledge and determine goals, rules of practice, and necessary training (Abbott, 1998; Freidson, 1986). Professionalization is the process by which experts gain autonomy from non-experts. A field of knowledge moves closer to a profession when it holds a core set of values and judgments that prevail over other considerations. When imperatives that are external to a profession overrule judgments based on internal considerations, professionalism suffers. Inability to manage boundaries that define training credentials and skills or to use judgments that are based on core values undermines claims to professionalism.

As institutionalized in development agencies, communication hardly meets conventional professional requirements. It lacks a clear path of credentialism, particularly in the eyes of medical doctors, public health experts, or economists whose disciplines have welldefined training requirements. It includes a heterogeneous collection of people with training in a variety of fields. Nurses, journalists, public health graduates, and graphic designers among other staff with diverse training typically perform communication roles. Nor is there unanimity about expected competencies. 'Communication' is a title applied to staff whose job description ranges from materials design to media relations.

The weakness of communication as a profession is particularly noticeable in organizational contexts dominated by strongly institutionalized professions such as medicine and economics. Medical doctors and economists hold privileged positions in development institutions (McNeill, 2005). Unlike other disciplines that have become 'professionalized' in the field of development in the past decades (Kothari, 2005), communication has remained underdeveloped. In institutions dominated by disciplines that embody the conventional scientific model, communication is seen as bereft of scientific heft. It does not fit the traditional model of scientific knowledge defined by quantitative methodologies, experimentation, rigor, and predictability. My point is not to argue that communication is or should be a science in the mold of the modern paradigm. Rather, my argument is that as long as communication maintains a dependent relation visà-vis the professions that define development objectives, it remains under the intellectual tutelage of the prevalent disciplinary paradigms that determine development goals and approaches.

In the case of communication in global health programs, the hegemony of medicalization determines institutional expectations of communication. Medicalization entails the expansion of medical jurisdiction over health (Conrad, 2007). Even when non-medical factors are acknowledged, such as social, economic, and cultural factors underlying illness and disease, addressing health problems is conflated with medical interventions. Medicalization displaces perspectives that engage with specific socio-cultural and political aspects of individual communities. Because it often promotes universal medical solutions to tackle diseases, it makes local knowledge and conditions irrelevant. Randall Packard (1997) has shown the hegemony of a medicalized approach in malaria control in the 1940s and 1950s. It ignored not only local knowledge and actions to control malaria, but also 
economic conditions and social dynamics that affected both the propagation of the mosquito vector as well as possible solutions. Similar arguments have been made about the global medicalization of HIV/AIDS (Parker, 2000) and women's health (Knudsen, 2006).

Medicalized approaches put communication in the role of a transmission belt of medical knowledge in global health programs as demonstrated by countless programs that expect communication to disseminate information to achieve several goals such as increase the use of family planning and immunization services, improve access and correct use of insecticide-treated nets to prevent malaria, and change child feeding habits. Communication has been expected to contribute to expand the reach of vaccines, drugs, and technologies by drumming up demand and teaching people their benefits and uses. Likewise, journalism training and peer-education activities, which typically fall under the purview of communication programs, are typically intended to popularize medical knowledge to correct misperceptions and ignorance about disease causation and care.

Medicalization also is influential in informational approaches to communication in global tuberculosis programs (Waisbord, 2007). Despite some innovative and promising efforts to expand the current perspective, the biomedical paradigm underlies the uses of communication. Not only do programs rarely address social and cultural issues affecting tuberculosis, but they also typically support a vision of communication that ignores local factors that affect care-seeking and treatment. With a few exceptions, programs basically task communication with spreading the same 'technical' messages (e.g. forms of transmission, availability of care) without considering a host of socio-cultural and economic factors that determine people's perspectives and decisions on healthcare. Medicalization tilts communication in favor of informational approaches and away from participatory communication. It asks communication to disseminate knowledge to support predetermined strategies rather than a citizen-led process of dialogue and decision-making, to convey expert information rather than promote local knowledge, and to support technical solutions rather than help communities to identify a range of interventions to address health challenges.

\section{Technical solutions to political problems}

The third obstacle to institutionalizing participatory communication is the prevalence of a technical mindset over a political perspective. Development programs are antithetical to politics. As anthropologist James Ferguson (1990) has aptly put it, development works as an 'anti-politics machine' that negates fundamental political issues related to social stratification and collective action. Although programs largely reflect the politics of donor countries and members, they are purposefully divorced from local politics. A mix of political and geopolitical concerns, the domestic politics of donor countries, and charity and paternalistic sentiments influence the goals of development programs. Despite the influence of political dynamics and interests, programs are typically presented as technical endeavors based on scientific evidence to achieve humanitarian goals that are beyond politics. The language of science is used to ground programmatic prescriptions and keep political considerations at a distance. Several authors have indicated that development agencies are not dependent on the 'states' that created and fund them, and that considerable margins of 'organizational autonomy' exist in international organizations (Barnett \& Finnemore, 1999). To keep states and domestic politics at a distance, agencies ground their legitimacy on the rational-legal authority that they represent as well as their control over technical expertise. Development programs justify goals and actions on the basis of technical rationality rather than politics. 
The aversion to taking a political perspective is widespread in the field of global health. Agencies such as the World Health Organization or specific units within organizations (e.g. health programs in the World Bank and bilateral donors such as USAID) essentially provide technical support to governments and civic organizations and carefully navigate both international and domestic politics. This situation presents a paradoxical situation: Technical organizations are tasked with addressing problems that are political in nature. How can health systems be strengthened, the quality of services be improved, or access to healthcare be expanded without politics? How do excluded populations become empowered without politics? How can health budgets be increased without reshuffling the political priorities of local and national governments? In contexts of poverty and social exclusion, collapsed health infrastructures are one of the most formidable problems to promote health and control diseases among the world's poor (Garrett, 2007). Reasons for persistent structural problems include meager budgets for social programs, poor and corrupt management, the lack of political clout of rural and peri-urban populations, and insufficient and inadequately trained staff. It is hard to envision how these conditions can be corrected, let alone overturned, without political action through which subaltern communities, women, or indigenous populations effectively wrestle power away from dominant groups. Technical solutions are insufficient to address problems rooted in political inequalities.

Putting politics at the forefront of development agendas, however, is anathema to an institutional mindset that carefully avoids local politics. Tiptoeing local politics is a rule of thumb for development officials who need to maintain civil relations with domestic actors (particularly governments) to ensure that programs run smoothly through bureaucratic mazes. Questioning the decisions of governments or other local 'recipients' might alienate partners and bring unwanted controversies.

'Professionalism' is the best strategy to avoid getting tangled in politics. What 'professionalism' means is not clear. It is rather an abstract notion frequently bandied about to praise someone's job performance. As Stirrat (2000, p. 35) perceptively observes, in the context of development programs, professionalism 'alludes to such features as an ability to cooperate with others, technical competence, a recognition of disciplinary boundaries and complementarities, and an ability to work to deadlines.' Regardless of specific skills, professionalism entails, above all, sticking to technical arguments and complying with bureaucratic procedures. Because politics cannot interfere with normal routines and expectations (e.g. timely disbursement of funds, contracts that meet regulations), they require, to paraphrase Max Weber, technical 'specialists without political spirit.' Technical rationale trumps personal and organizational politics. Decisions are bound by an institutional rationality anchored in scientific and bureaucratic justifications rather than political arguments. The consolidation and enforcement of bureaucratic procedures entails leaving politics out (Feldman, 2003).

Participatory communication uneasily fits an institutional mindset that is wary of confronting politics. It introduces the prospect of conflicts generated by rural communities questioning programs that benefit urban elites, women demanding empowerment, youth disapproving decisions made by elders, or communities criticizing decisions that favor specific religious and ethnic groups. Social change is a political rather than a technical process through which power relations change, priorities are reshuffled, and resources are redistributed. 


\section{Changing the system or organizational imperatives?}

To recapitulate the argument presented: theoretical innovations in the academic field have not been sufficient to change practices and views about communication inside aid organizations. The incorporation of participatory communication has been limited by institutional imperatives and professional cultures. Demands for organizational publicity, the subsidiary role of communication within dominant 'epistemic communities,' and the hegemony of a technical mindset that favors informational approaches to communication and discourages the use of models that put politics at the center.

Several questions need to be asked to contemplate the prospects of participatory communication in development programs. If participatory communication goes against prevalent organizational imperatives, how can it be fully institutionalized? If politics is at the heart of social change, how to incorporate participatory communication in institutions that prefer to keep local politics at a long arm's distance? Is it a matter of changing institutional incentives and procedures? Does it require a substantive overturn of prevailing disciplinary mindsets? Is it inevitably 'wishful thinking' given entrenched organizational cultures and hierarchical nature of development agencies? Given institutional needs and professional reputation, are communication offices the best platforms to promote participatory communication inside development agencies?

These questions need to be approached from a perspective that considers how international agencies incorporate changes and shift programmatic priorities.

One needs to have moderate hopes for the institutionalization of communication thinking and practice that foregrounds participation in terms of the relevance of local knowledge and decision-making. The organizational obstacles for participatory communication are similar to the ones that have frustrated efforts to introduce ideas and practices that emphasize community participation and public accountability in international aid. A burgeoning literature in international relations has examined the weight of organizational cultures in changes of policy orientation and programmatic direction in aid institutions (Leiteritz, 2005). Academic interest has been largely motivated by recent calls for the reform of major development agencies in light of strong criticisms particularly of the International Monetary Fund and the World Bank and several United Nations agencies. In the past decade, there has been growing discontent with development priorities worldwide. Former officials have written eloquent critiques of the aid system (Ellerman, 2006; Stiglitz, 2000). Globally, communities have demanded inclusion and participation in decisionmaking based on concerns about the past and future impact of a variety of projects (Clark, Fox \& Treakle, 2003). Anti-globalization groups have staged high-profile protests to demand a complete overhaul, if not the demolition, of the current foreign aid system. Amidst growing criticisms, there is wide skepticism about the possibilities of change inside aid and development agencies (Barnett \& Finnemore, 2004; Krasno, 2004; Nielson, Tierney \& Weaver, 2006). Institutions are not indifferent to fierce criticisms, picketing and bad press, but sensitivity to criticism does not prompt profound changes.

Why is change so difficult? Why is skepticism about change in the aid system so widespread? Studies demonstrate that organizational cultures are powerful obstacles to change even when agencies are sensitive to mounting criticisms and external pressures. Despite grand pronouncements in favor of change, few and significant transformations have actually taken place. 'Organizational hypocrisy' (Brunsson, 2002; Lipson, 2006), rather a genuine commitment to innovation, is prevalent. Conventional technocratic rationality and built-in incentives are obstacles against the push for accountability and broad participation of affected communities. Overturning the current system of priorities 
and expanding the dominant technical mindset is a significant departure from the current order. Participatory communication sets out an ambitious goal: to change the 'problem definition' inside the 'epistemic communities' (Haas, 1990) that dominates development organizations. It asks several tough questions: How to envision the role of communities in the global identification of challenges and solutions in a multi-leveled and bureaucratized world? How to democratize the standard process by which global problems are defined and objectives declared for billions of people? How to incorporate lay knowledge into technical assessments? Answering these questions as well as achieving participatory goals implies a radical shift in the dominant mindset. In organizations where health or economic technical knowledge is hegemonic, institutionalizing ideas from the social sciences such as participatory politics and the value of 'local knowledge' is tantamount to an intellectual revolution (Potvin, Gendron, Bilodeau \& Chabot, 2005).

While I share the skepticism about the prospects of massive changes, I believe that gradual yet significant innovations are possible within institutional constraints. A serious commitment to participatory communication is improbable within the current system of development and foreign aid. Bureaucracies, as sociologists since Wilfred Pareto and Max Weber have persuasively argued, are not paragons of democracy. Promoting participatory communication is antithetical to vertical organizations. However, even amidst the notoriously fickle attention of donors and the technical-bureaucratic imperatives of agencies, it is important to recognize the achievements of experiences in bottom-up participation. They have shown that if they are based on local ownership and a viable plan for sustainability and scale they can intelligently link with international agencies. The work of women's groups around health and other issues such as the cases of SEWA in India (Ranson, Sinha, Chatterjee, Acharya, Bhavsar, Morris \& Mills, 2006) or the mobilization of communities affected by HIV/AIDS such as the Treatment Action Campaign in South Africa, for example, suggest that participatory initiatives achieve moderate successes while maintaining linkages with international agencies and donors. The gradual importance of health advocacy and social movements suggests that progress can be made even when the global aid system is skewed towards prioritizing quick technological fixes and medical magic bullets.

Is it feasible to practice organizational jujitsu by using the weight of bureaucratic imperatives to favor participatory communication? Can current institutional incentives be shifted in ways that bureaucratic procedures are used to promote participation? If organizational incentives dictate that 'moving funds smoothly' and 'meeting deadlines' are mandatory, can those incentives be utilized to promote participatory communication? It is hard to envision change without top-level commitment to institutionalize different conceptions of communication. Persuading technical staff who know little or hold narrow perceptions about communication about the contributions of participatory actions is plausible, particularly if they are linked with similar approaches that have originated in other disciplines such as, in the case of global health, community-based health, governance, and social capital (Cornish \& Ghosh, 2007; Monkman, Miles \& Easton, 2007).

Institutionalizing participatory communication is not just a matter of affecting bureaucratic norms. Rather, it entails overhauling a technical rationality that finds participatory politics and democratic communication foreign to institutional missions. The challenge is different from persuading technical experts to adopt concepts from other disciplines, as famously happened in the World Bank when President James Wolfensohn and his close advisors strongly supported the adoption of 'social capital' and 'governance' in an institution dominated by economists (Fine, 1999; McNeill, 2005). Participatory 
communication goes against the institutional grain of global health organizations and programs. While technical goals offer a clear and tangible mandate for professionals trained and experienced in health, participatory communication falls outside individual and institutional expertise. Moreover, participation foregrounds politics, a radioactive notion for a technical mindset that feels comfortable staying 'professional' and avoiding meddling with local politics. Participation questions dominant notions that associate 'health communication' with relaying experts' medical knowledge.

Because communication is foreign to high-level decisions about development, it is at a huge disadvantage to expand and transform prevailing institutional expectations and roles. Its situation is different from health experts pushing for alternative approaches to strengthening healthcare systems or economists trying to persuade their colleagues to move beyond neoclassical models in development policies. Communication is in a different institutional position inside development agencies. Even if it has solid, evidence-based arguments about the contributions of participation to address health and development challenges, certainly a key requirement in organizations that uphold the scientific model, communication is at disadvantage to push for a 'paradigm shift.'

The institutionalization of participatory communication is at a crossroads. Future efforts could be directed at revolutionizing widespread conceptions of communication and/ or 'hitching the communication wagon' to ongoing initiatives to strengthen accountability, human rights, and local participation in international aid. Opportunities vary across agencies and governments as well as across specific social sectors. It is not obvious what route is most suitable as the international aid system remains the subject of political and academic scrutiny. It behoves researchers and practitioners to seriously consider the prospects and strategies for broadening the understanding of communication in international development. This requires embracing an analytical perspective that examines organizational dynamics and professional micropolitics to assess how alternatives to the informational paradigm might be effectively institutionalized in development agencies.

\section{Notes}

1. Telling signs to eschew 'development' in favor of 'social change' are the recent decision of the former International and Development Communication division of the International Communication Association to change its name to Global Communication and Social Change, and the launch of the journal Communication for Development and Social Change.

2. The situation varies across organizations and in different periods. The World Bank, for example, has a sizable 'development program' unit with tasks that go beyond the typical 'press relations offices' and provide support to a variety of projects on participatory communication, training, and behavior change communication. Until the unit was dismantled a few years ago, UNICEF had a 'program communication' unit in its New York headquarters that worked closely with technical areas, particularly in health and children's rights. Likewise, the Food and Agricultural Organization had a 'program communication' unit that collaborated with technical offices on participation and other issues. The situation in the World Health Organization is complex and hard to generalize. As it widely varies across technical units and levels (global, regional, and country). While at the global level there are some programs (e.g. HIV/AIDS) with specific communication officers who perform typical information functions and/or substantive functions closely linked to technical goals, communication staffing resources and skills are much thinner in regional and country offices. In general, only a few regional offices have communication officers working on technical issues. The majority rely on support from 'public relations' units typically staffed by press officers and other officers with expertise in media relations. 


\section{References}

Abbott, A. (1998). The system of professions: An essay on the division of expert labor. Chicago: University of Chicago Press.

Barnett, M., \& Finnemore, M. (1999). The politics, power, and pathologies of international organizations. International Organization, 53, 699-732.

Barnett, M., \& Finnemore, M. (2004). Rules for the world: International organizations in global politics. Ithaca, NY: Cornell University Press.

Bebbington, A, Guggenheim, S., Olson, E., \& Woolcock, M. (2004). Exploring social capital debates at the World Bank. Journal of Development Studies, 40(5), 33-64.

Blanchet, K. (2001). Participatory development: Between hopes and reality. International Social Science Journal, 53, 637-641.

Brunsson, N. (2002). The organization of hypocrisy: Talk, decisions and actions in organizations (2nd ed). Oslo: Liber/Anstrakt/Copenhagen Business School Press.

Chambers, R. (1997). Whose reality counts? Putting the first last. London: ITT Publications.

Chambers, R. (2007). Participation and poverty. Development, 50(2), 20-25.

Clark, D., Fox, J. \& Treakle, K. (Eds.). (2003). Demanding accountability: Civil society claims and the World Bank Inspection Panel. Lanham, MD: Rowman \& Littlefield.

Cleaver, F. (2001). Institutions, agency and the limitations of participatory approaches to development. In B. Cooke \& U. Kothari (Eds.), Participation: The new tyranny (pp. 36-55). London: Zed Books.

Conrad, P. (2007). The medicalization of society. Baltimore: Johns Hopkins University Press.

Cooke, B., \& Khotari, U. (Eds.). (2001). Participation: The new tyranny? London: Zed Books.

Cornish, F., \& Ghosh, R. (2007). The necessary contradictions of 'community-led' health promotion: A case study of HIV prevention in an Indian red light district. Social Science \& Medicine, 64, 496507.

Cornwall, A. (2007). Buzzwords and fuzzwords: Deconstructing development discourse. Development in Practice, 17, 471-484.

Cottle, S., \& Nolan, D. (2007). Global humanitarianism and the changing aid-media field: Everyone was dying for footage. Journalism Studies, 8, 862-878.

Davenport, S.B., McKinley, M., Ventsam, S., \& Elias Valdeavellano, E. (2002). Fostering reproductive health through entertainment-Education in the Peruvian Amazon: The social construction of Bienvenida Salud. Communication Theory, 12, 192-205.

Edwards, M. (1999). International development NGOs: Agents of foreign aid or vehicles for international cooperation? Nonprofit and Voluntary Sector Quarterly, 28(1), 25-37.

Ellerman, D. (2006). Helping people help themselves: From the World Bank to an alternative philosophy of development assistance. Ann Arbor: University of Michigan Press.

Escobar, A. (1995). Encountering development: The making and unmaking of the Third World. Princeton, NJ: Princeton University Press.

Feldman, S. (2003). Paradoxes of institutionalization: The depoliticisation of Bangladeshi NGOs. Development in Practice, 13(1). Retrieved 20 April 2008 from http://www.developmentinpractice. org/apc_ae-v13n1x524686.html

Ferguson, J. (1990). The anti-politics machine: Development, depoliticization, and bureaucratic power in Lesotho. Cambridge: Cambridge University Press.

Fine, B. (1999). The developmental state is dead, long live social capital. Development and Change, 30, $1-19$.

Freidson, E. (1986). Professional powers: A study of the institutionalization of formal knowledge. Chicago: University of Chicago Press.

Garrett, L. (2007). The challenge of global health. Foreign Affairs, January/February. Retrieved December 10, 2007 from http://www.foreignaffairs.org/20070101faessay86103/laurie-garrett/thechallenge-of-global-health.html

Gumucio-Dragon, A. (2001). Making waves: Stories of participatory communication for social change. New York: The Rockefeller Foundation.

Gumucio-Dragon, A. (2006). Knowledge, communication, development: A perspective from Latin America. Development in Practice, 16(6). Retrieved 20 April 2008 from http://www.development inpractice.org/apc_ae-v16n6x542370.html

Haas, E. (1990). When knowledge is power. Berkeley \& Los Angeles: University of California Press.

Hickey, S., \& Mohan, G. (2005). Relocating participation within a radical politics of development. Development and Change, 36, 237-262. 
Holland, J., \& Blackburn, J. (Eds.). (1998). Whose voice? Participatory research and policy change. London: IT Publications.

Huesca, R. (2003). From modernization to participation: The past and future of development communication in media studies. In A. N. Valdivia (Ed.), A companion to media studies (pp. 50-71). Malden, MA: Blackwell.

Jacobson, T., \& Servaes, J. (Eds.). (1999). Theoretical approaches to participatory communication. Cresskill, NJ: Hampton Press.

Knudsen, L. (2006). Reproductive rights in a global context. Nashville, TN: Vanderbilt University Press.

Kothari, U. (2005). Authority and expertise: The professionalization of international development and the ordering of dissent. Antipode, 37, 425-446.

Krasno, J. (Ed.). (2004). The United Nations: Confronting the challenges of a global society. Boulder, CO: Lynne Reinner.

Leal, P. (2007). Participation: The ascendancy of a buzzword in the neo-liberal era. Development in Practice, 17, 539-548.

Leiteritz, R. (2005). Explaining organizational outcomes: The International Monetary Fund and capital account liberalization. Journal of International Relations and Development, 8, 1-26.

Lipson, M. (2006). Organized hypocrisy and global governance: Implications for United Nations reform. Paper presented at the conference of the International Studies Association, San Diego, CA, March.

Macdonald, L. (1995). NGO and the problematic discourse of participation: Cases form Costa Rica. In D.B. Moore \& G.J. Schmitz (Eds.), Debating development discourse: Institutional and popular perspectives (pp. 201-229). Basingstoke: Macmillan.

Mato, D. (2004). Communication for social change in Latin America: Contexts, theories, and experiences. Development in Practice, 14, 5.

McNeill, D. (2005). Power and ideas: Economics and global development policy. In D. Stone \& S. Maxwell (Eds.), Global knowledge networks and international development (pp. 57-71). London: Routledge.

Melkote, S., \& Steeves, L. (2001). Communication for development in the Third World: Theory and practice for empowerment. Thousand Oaks, CA: Sage.

Monkman, K., Miles, R., \& Easton, P. (2007). The transformatory potential of a village empowerment program: The Tostan replication in Mali. Women's Studies International Forum, $30,451-464$.

Morris, N. (2003). A comparative analysis of the diffusion and participatory models in development communication. Communication Theory, 13, 225-248.

Mosse, D. (2005). Cultivating development: An ethnography of aid policy and practice. London: Pluto Press.

Moxham, B. (2005). The World Bank's land of kiosks: Community driven development in TimorLeste. Development in Practice, 15, 522-528.

Nielson, D.L., Tierney, M.J., \& Weaver, C.E. (2006). Bridging the rationalist-constructivist divide: Re-engineering the culture of the World Bank. Journal of International Relations and Development, 9, 107-139.

Packard, R. (1997). Visions of postwar health and development and their impact on public health interventions in the developing world. In F. Cooper \& R. Packard (Eds.), International development and the social sciences: Essays on the history and politics of knowledge (pp. 93-118). Berkeley \& Los Angeles: University of California Press.

Parker, R. (2000). Administering the epidemic: HIV/AIDS policy, models of development, and international health. In L.M. Whiteford \& L. Manderson (Eds.), Global health policy, local realities: The fallacy of the level playing field (pp. 39-56). Boulder, CO: Lynne Reinner.

Potvin, L., Gendron, S., Bilodeau, A., \& Chabot, P. (2005). Integrating social theory into public health practice. American Journal of Public Health, 95, 591-595.

Ranson, K.M., Sinha, T., Chatterjee, M., Acharya, A., Bhavsar, A., Morris, S.S., \& Mills, A.J. (2006). Making health insurance work for the poor: Learning from the Self-Employed Women's Association's (SEWA) community-based health insurance scheme in India. Social Science \& Medicine, 62, 707-720.

Robb, C.M. (2002). Can the poor influence policy? Participatory poverty assessments in the developing world. Washington: The World Bank and the International Monetary Fund. 
Rogers, E. (1976). Communication and development: The passing of the dominant paradigm. Communication Research, 3, 213-240.

Rogers, E. (2004). A prospective and retrospective look at the diffusion model. Journal of Health Communication, 9, 13-19.

Sachs, W. (1991). The development dictionary: A guide to knowledge as power. London: Zed books.

Stiglitz, J. (2006). Making globalization work. New York: W. W. Norton.

Stirrat, R.L. (2000). Cultures of consultancy. Critiques of Anthropology, 20, 31-46.

Tufte, T., \& Hemer, O. (Eds.). (2005). Media \& glocal change: Rethinking communication for development. Buenos Aires: Nordicom \& CLACSO.

Uphoff, N. (1985). Fitting projects to people. In M. Cernea (Ed.), Putting people first: Sociological variables in rural development (pp. 369-378). Oxford: Oxford University Press.

Waisbord, S. (2000). Family tree of theories, models and approaches in development communication. The Communication Initiative. Retrieved 20 April 2008 from www.comminit.com

Waisbord, S. (2006, May 15). When training is insufficient: Reflections on capacity development in health promotion in Peru. Health Promotion International. Retrieved 20 April 2008 from http:// heapro.oxfordjournals.org/cgi/content/abstract/dal018v1

Waisbord, S. (2007). Beyond the medical-informational model: Recasting the role of communication in tuberculosis control. Social Science \& Medicine, 65, 2130-2134.

Waisbord, S. (2008, forthcoming). Missed opportunities: Communication and the Polio Eradication Initiative. Communication for Social Change.

White, S. (1994). Participatory communication: Working for change and development. New Delhi: Sage.

White, S. (1999). The art of facilitating participation: Releasing the power of grassroots communication. Thousand Oaks, CA: Sage.

Wilkins, K.G. (Ed.). (2000). Redeveloping communication for social change: Theory, practice, and power. Lanham, MD: Rowman \& Littlefield Publishers.

Wilkins, K.G., \& Mody, B. (2001). Reshaping development communication: Developing communication and communicating development. Communication Theory, 11, 385-396. 
Copyright of Social Identities is the property of Routledge and its content may not be copied or emailed to multiple sites or posted to a listserv without the copyright holder's express written permission. However, users may print, download, or email articles for individual use. 